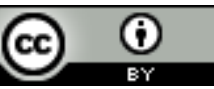

LECTIO PRAECURSORIA

Ylva Grufstedt

\title{
Counterfactual history and game design practice in digital strategy games
}

In a remarkable development 0ver the last 30 or so years, digital games have stepped into the mainstream as an important vehicle of technological, social, political and, of course, historical discourse. Some of the games are particularly concerned about historical change, playing with the past, not just in it. Digital strategy games Europa Universalis IV and Hearts of Iron IV by Paradox Development Studio are two. In such games, the player may take control of a person or a nation and create their own timeline and outcomes of history. Or, at least, this is the illusion. Games aren't in fact magical. They are intentionally designed artefacts. They are carefully balanced, sophisticated, yet rarely as chaotic as they may seem. What, then, constitutes the moving parts of historical representation in games, and how are we to understand the specific role and positioning of counterfactual history, here?

Scholarly debate on historical games has long been centered on the exceptional and on the ways that games are interactive, unlike movies or books. But there is another aspect to this. In what ways are games part of a sameness?

In other words, what shared spaces, uses and perpetuations of historical understandings are games and game making both reliant on, and exist in support of?

I here suggest that, embedded in digital strategy games, and their inherently counterfactual content, lie intricate historical cultural signalling.

Historical culture being the collection and use of historical references and contextually attributed meanings, frames and supports the use of the past in any context. The context, here, is game design practice. In other words, game development practices that incorporate and frame history as a meaningful aspect of gameplay.

Subsequently, counterfactuals in this context are a consequential puzzle piece to the way games fall in line with - or, importantly, reject - historical culture and communication through design. Counterfactual history, here, are representations of alternative historical processes, paths-not-taken and outcomes based on bistorical reference.

And when I say consequential in the context of game design, I mean that in at least two ways. Firstly, in the way historical counterfactuals here reflect on historical theory and our understanding of the epistemological tensions between the academic and non-academic, and related understandings of what historical counterfactuals can, be and do, or not. 
Secondly, historical counterfactuals are consequential in the way they embody developer views on player expectations, and notions of fun and entertainment. As such, they are a crucial aspect of how game design principles impose themselves on the representation of the past, and vice versa.

In other words, it seems counterfactual history in games provide an opportunity to study and discuss both history and game design in tandem.

Counterfactuals, then, act as pieces in a great game of historical communication in the present. An important distinction here is that counterfactual scenarios rarely are completely "original". They do not argue completely open-endedly, but within a set of rules, often manipulated and curated on a caseby-case basis, using the building blocks of historical reference.

\begin{abstract}
What would it take to re-establish Austria-Hungary? If only the First World W ar had never happened! What elements were crucial for the inception of the First World War? What would the world have looked like if the First World W ar had never happened? If the assassination of the archduke had not happened, how likely is it that the First World War would have happened? What were the odds of the First World War taking place?
\end{abstract}

These are all questions that engage with antecedents and consequence, and continuity and change, but at a closer look we may also distinguish between how and why they do it. In the thesis I argue that counterfactual scenarios in Europa Universalis IV and Hearts of Iron IV may be framed as wishful thinking, possible worlds and future fictions - theoretical concepts that describe how counterfactuals reflect types of uses of history.

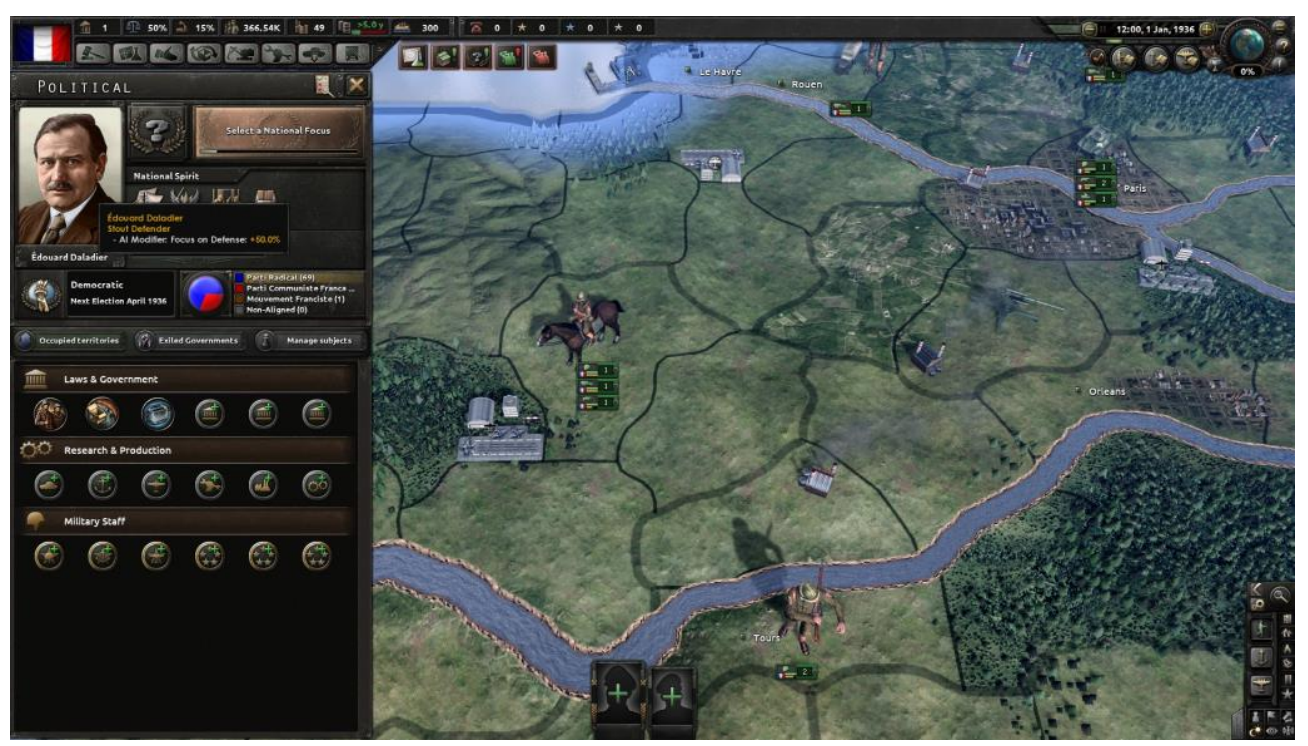

A screenshot from the game Heart of Iron IV. Picture taken by Ylva Grufstedt.

Because playing in Early Modernity in Europa Universalis IV and being asked to reignite the idea of a Roman Empire, evokes one element of the past to be reframed within another. The player is being asked to create a geographical Roman Empire in its glory days but within the framing of the Early Modern period.

In that sense, and for all of the similar examples of counterfactuals like this in Europa Universalis, it is not just a game about the Early Modern period. It is also in significant ways a game about all of the other historical references - and more importantly, about, in this example at least, the Roman Empire as 
a historical cultural artefact with a role to play, here, today. That is to embody notions of reconstitution, reimagination and repercussion.

For game designers, then, counterfactual history is almost never about depicting the historically most probable outcomes. To them, authorship is about determining what the most advantageous outcomes from a design and gameplay perspective are. In other words: how are they to create the most entertaining, challenging and engaging gameplay experience possible for their players?

I have found that design practice in this context aligns with two primary focuses: player-centred design, and entertainment-centred design. Advantageous, here, require developers to navigate the contexts and frameworks that guide, influence and / or prompt decision-making as regards these design goals. Building on the work of Annakaisa Kultima, game development - as it pertains to the representation of the past - is guided and framed by an industry-specific ecosystem that ultimately frames and shapes the representation of history and counterfactual history in the games.

"Shaping" history, as it were, happens in many different instances. The most intuitive level for most of us is of course the designing of game itself. But, as I aim show here, the immediacy with which game design practice happens in code, in asset design, in mechanics design, does not extend to next tier contexts such as monetisation models, promotional activity, player expectations etc.

These industry variables are considerably slower, more rigid and stringent than hands-on development. They are however necessary to consider in a holistic analysis of what contexts and framings influence historical representation in games. As regards Europa Universalis IV and Hearts of Iron IV, development happens in increments, meaning pods of content and polish are added to the game over time. Very rarely is anything removed. In the thesis, I call this a principle of completionism, a term derived from gaming culture jargon to emphasise two things.

Firstly, scope and detail as a design objective, meaning that the more content a game has, the more finished it appears to be. It also makes sure players can come back and have new experiences with the games. And, secondly, the DLC economy makes sure of the developers' ability to charge players repeatedly.

But what has this got to do with history? It is my assessment that digital distribution, incremental DLC releases, monetisation, player-retention and accessibility values - completionist practices - frame representation considerably. Among other things, it supports replayability and multiplicity of content. But this is not an inherently positive thing and must be reconciled by design. Over time, complexityreduction and stagnation with regard to mechanics and synergy appears to be one of its casualties, leaving some of the fundaments intact over time. A typical example is the trade-system in Europa Universalis IV, which was originally made to showcase the importance of Venice as a trading-hub in the 1400's and to this day largely fails to depict any other kind of trade, or - to be sure - fails to facilitate counterfactual history in the vein of mechanics such as historical missions or national focus trees.

In trying to understand, then, what the effects of design practices are on the representation of the past and counterfactuals here, we may consider not just what is being designed, but also, what isn't. Epistemologically speaking, developers engage with history on two primary grounds 1) as already discussed, as wranglers of the past for the benefit of game making and 2) as proficient readers of history.

Because game developers at Paradox Development Studio, to be sure, are well read on history. But there is a blatant exercise in cherry-picking going on here as well, which I argue stems from the contradictory relationship between the design legacy of conflict-driven gameplay and developer understandings of player expectations, as well as their understandings of the games' position in a greater societal context. Because central to this whole discussion is, the question of how developers balance their understanding of the past with a delimiting sense of what kind of history is specific to the gameplay experience. 
In other words, the conflict and militaristic focus on gameplay values in both games, in itself partly a result of continuity in gaming culture, is used to rationalise the omission of content such as civilian hardship in the wake of war, representations of people other than men, childhood, ecology, and more. A typical consequence of this is the omission of The Holocaust and Nanking Massacre in Hearts of Iron $I V$, both of which are essentially banned from the games and discussion forums. In juxtaposing this practice with the prevalence of trans-Atlantic slave trade in Europa Universalis IV, developers circle back to the argument about mechanics and agency noting that historical events that influence the gameplay experience, can be depicted if done correctly. But, as noted by Souvik Mukherjee, there are many sides to agency, and player- and entertainment-centered development practices that are wholly focused on gameplay agency, do not appear to take historical agency - or in the case of people enslaved, a complete lack thereof - into the equation.

As is hopefully becoming clearer, this is an inherently multidisciplinary effort, as are most game study ventures. Ultimately, synthesising theories and methodologies from several different research fields constitutes a necessary challenge. Game studies, in all its variety and multifaceted-ness, has grown very quickly over the past couple of decades. There is, in my opinion, a risk that - especially scholars coming from outside of game studies from adjacent fields such as social studies and the humanities - continuously reinvent the epistemic field due to lack of cohesiveness and overview. For this reason, the active formation of fields such as historical game studies has an important role to play. On the one hand, they organise the specific challenges of the unique combination of fields in a way that is both fair and suitably critical. On the other, they need a constant influx of meta-scholarship, evaluating strides in both fields for the benefit of the multidisciplinary approach. Thankfully, this approach reciprocally adds value to both history and game scholarship in return.

What's been sorely missing in this discussion regardless of disciplinary home is authorship, most specifically with regard to design. As noted by a meta-study on game studies publication keywords, the words "game design" are used disproportionally to the amount of research actually being conducted on game design work or game designers.

Happily, developer perspectives are getting quite a bit of attention recently, including a number of $\mathrm{PhD}$ theses and articles come out only in the last months. This is a positive development for critical historical game studies as game artefacts can be quite delimiting in telling us all that we want to know about them. The most fruitful studies on games are the ones that cannot only point to the occurrence of something but that are able to engage with several layers of meaning making, tilting our understanding of both games and history, simultaneously. 


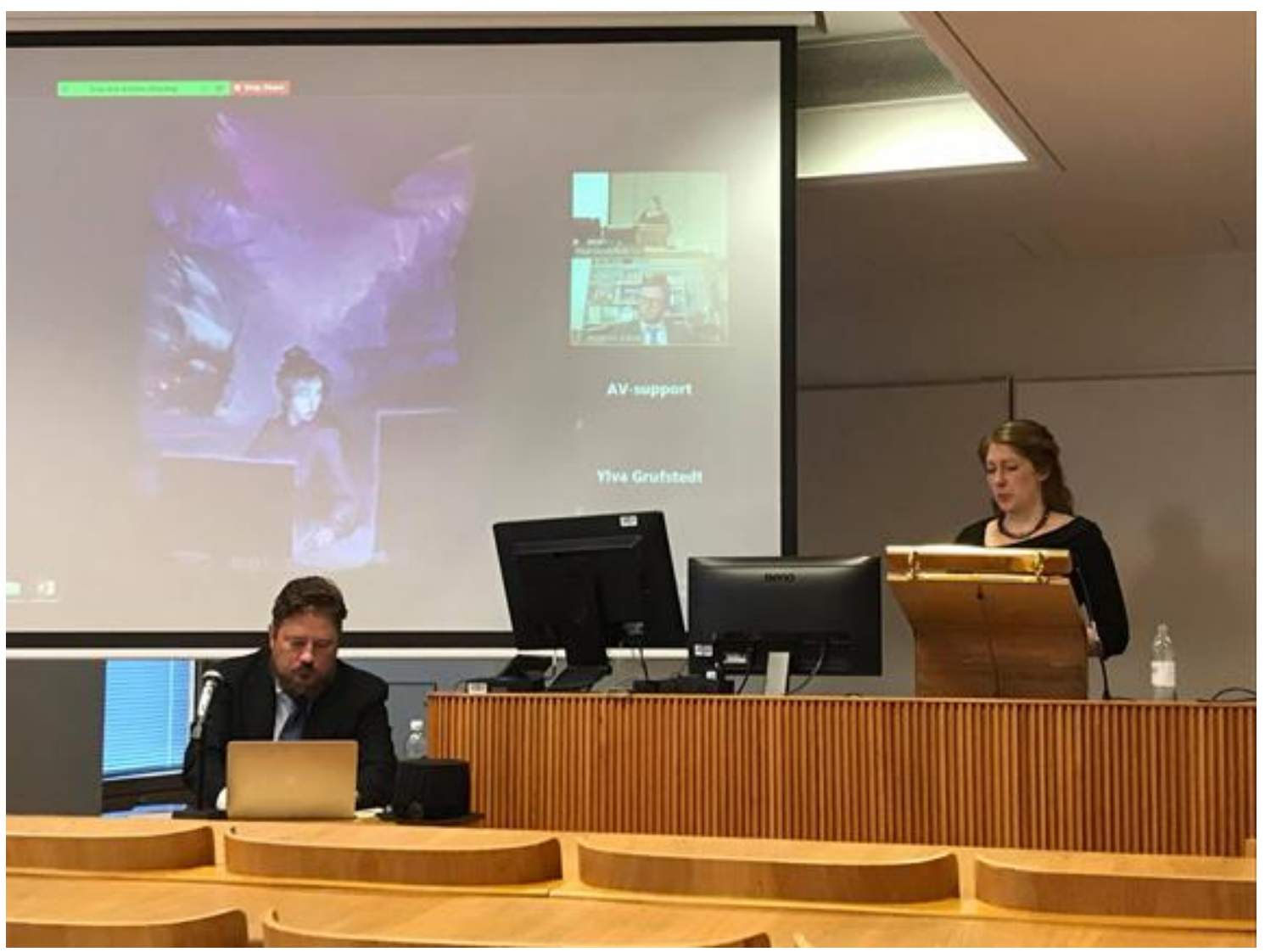

A picture from the defense taken by Charlotte Cederbom.

Throughout the period I spent working on this thesis I have often had to explain the difference between the history of games and history in games to those around me. At the present junction, I note that the history of games is indeed an important part of my results. Much more so perhaps than I had anticipated. Indeed, a historical perspective on games ended up having a central role in the explanation of certain factors in the thesis. I call the concept design legacy - a form of dowry in which change over time becomes a factor that helps explain why games look the way that they do. This is a surprisingly understudied aspect of game making, which has significant impact on the game artefact. In other words, game genealogy and the history of making games about the past add yet another layer to history depicted in games.

Historical games, then, occupy a space within these two overlapping contexts of game making and historical culture. The methodological approach is also twofold. The first part entailed going to the source at Paradox Development Studio and conduct interviews with developers and beta testers about designing historical games. The other approach was a study of the games in their parts. This means going back and forth between playing the games and opening them up - an anatomical study of their parts.

And I mean that quite literally. Part of my methodology has been the reading of game code. In the words of digital humanist Mark Sample, studying code and code commentary can "help us develop an understanding of games as cultural objects and of coding itself as cultural practice." I have made use of the fact that Paradox Development Studio allows most of their scripted content and localisation files to be open. This must be understood in the context of the game industry which continuously makes a point of hiding their work as to protect trade secrets. Paradox Development Studio keeps them open to allow players to modify their games. Surprisingly, no other scholar, to my knowledge has used this vast, completely plain text, material for studying history in Paradox grand strategy games. 
I here see the greatest potential for engaging with games not just as cultural object but as objects on the border between analogue and born digital. This is a material that has been continuously worked on and added to for almost 20 years, an accumulation of design knowledge and historical thinking, which is not only freely available but also happens to be in a format waiting to be analysed through datamining, visualisations, etc.

Finally, I will say something about transparency in game development and the role of researchers, not least historians. Otherwise unrelated from anything to do with the present thesis, the game industry is currently looking at a possible paradigm shift in terms of worker issues. Among other things, the notion of transparency is being discussed as regards to things like pay, hours worked, overtime, safety and other issues. Problems such as these in game development are not helped by a continued lack of transparency over-all. As researchers, we have a role to play here, in our critical work and also in terms of posterity. Game historians already struggle with collecting and preserving games, partly due to materialist reasons such as technology ageing out. However, we are currently also at risk of losing enormous amounts of context and data pertaining to the origins and making of games on a general level. The secrecy surrounding game-making is already a serious obstacle in doing research, and they make game design scholarship more difficult. Therefore, scholars with an interest in connecting to game design practices will simultaneously contribute to documenting the history of games and game making, an effort that, in my opinion should be treated with some urgency.

I would also like to underline that digital strategy games are far from the only genre to depict history and that different games do history differently. The Czech developed game Attentat 1942 explores actors and victims of The Holocaust in a way that can be considered both thoughtful and mediumconscious. When the game was going up on Google Play recently it was blocked just for mentioning the word Nazis. Here, the gameness of the product and historical cultural signalling seems incompatible. But, just because we can better explain why developers, or in the case of Google here publishers, make pragmatic, albeit polemic and sometimes problematic choices, of course, does not mean it is the best possible practice. As it happens, pragmatism and economy shouldn't be the antithesis of conscious application of historical understandings in games. This is one area where the game industry, as it stands, can probably do better.

FM Ylva Grufstedtin väitöskirja "Counterfactual history and game design practice in digital strategy games" tarkastettiin Helsingin yliopiston humanistisessa tiedekunnassa 14.8.2020. Vastaväittäjänä toimi Dr Andrew Elliott (University of Lincoln) ja kustoksena professori Mikko Tolonen.

Vä̈töskirjan tiivistelmä on julkaistu elektronisesti, ja se on luettavissa E-thesis-palvelun kautta osoitteessa bttp:/ / urn.fi/URN:ISBN:978-951-51-6262-5. 